\title{
Hot Ductility of Incoloy 901 Produced by Vacuum Arc Remelting
}

\author{
Fatemeh MOHAMMADI SHORE, ${ }^{1)}$ Maryam MORAKABATI, ${ }^{1)}$ Seyed Mehdi ABBASI, ${ }^{1)}$ Amir MOMENI')* \\ and Rashid MAHDAVI ${ }^{1)}$
}

1) Metallic Materials Research Center (MMRC-MA), Tehran, Iran, Tehran, Iran.

2) Materials Science and Engineering Department, Hamedan University of Technology, Hamedan, Iran.

(Received on November 23, 2013; accepted on January 16, 2014)

\begin{abstract}
Hot tensile testing was adopted over the temperature range of $850^{\circ} \mathrm{C}-1150^{\circ} \mathrm{C}$ and at strain rates of $0.001 \mathrm{~s}^{-1}-1 \mathrm{~s}^{-1}$ to study the hot ductility of Incoloy 901 . Hot ductility of the material was optimized in range of $950^{\circ} \mathrm{C}-1050^{\circ} \mathrm{C}$ and descended at either higher or lower temperatures. Dynamic recrystallization was the reason for the improvement of ductility at high temperatures. At lower temperatures, e.g. $850^{\circ} \mathrm{C}$, dynamic precipitation of intermetallic phases could effectively inhibit dynamic recrystallization and resulted in poor hot ductility.

At very high temperatures, e.g. $1150^{\circ} \mathrm{C}$, the hot ductility drop was due to the decohesion of particles/ matrix interfaces. The insensitivity of material to flow localization was understood from the monotonic increase of the strain rate sensitivity over the studied temperature range. The peak strain of the material unexpectedly increased with increasing temperature up to $1050^{\circ} \mathrm{C}$ and then decreased at higher temperatures. These results accounted for the possibility of dynamic precipitation of intermetallics at temperatures below $1050^{\circ} \mathrm{C}$ and thereby delaying dynamic recrystallization. The hyperbolic sine constitutive equation was used to describe the dependence of tensile stress on deformation temperature and strain rate and the corresponding material constants were determined. The average apparent activation energy for the initiation of dynamic recrystallization was determined as $359 \mathrm{~kJ} \mathrm{~mol}^{-1}$.
\end{abstract}

KEY WORDS: superalloys; hot tensile test; hot ductility; constitutive equation.

\section{Introduction}

Hot deformation is a crucial step in the processing of many industrial alloys including superalloys. The ductility of metals and alloys under hot working conditions depends on some intrinsic and extrinsic parameters. The intrinsic parameters affecting hot ductility are materials dependent and actually vary as functions of chemical composition. On the other hand, the extrinsic parameters of ductility are governed by the processing variables of temperature, strain rate and strain.

In general, alloying elements that are routinely added to raise strength or to improve the high temperature performance of superalloys, degrade the hot ductility of material and limit the safe processing to certain deformation regimes. Concern of low hot ductility is why the hot deformation behavior of superalloys has drawn much attention in the recent decades. ${ }^{1-5)}$ The existence and segregation of detrimental elements such as Sulfur and phosphorous to the grain boundaries has been known very detrimental to the intrinsic ductility of steels and superalloys. ${ }^{6}$ For this reason, the advanced techniques such as electro-slag remelting (ESR) and vacuum arc remelting (VAR) are often used for clean ingot casting of special steels and superalloys. ${ }^{7,8)}$ Although they have known very useful to limit the deleterious atoms

* Corresponding author: E-mail: ammomeni@aut.ac.ir DOI: http://dx.doi.org/10.2355/isijinternational.54.1353 in the starting ingots, but their influence on the hot ductility of superalloys has not been studied or compared in detail.

The restoration processes of dynamic recovery (DRV) and dynamic recrystallization (DRX) are crucial phenomena that affect the intrinsic ductility of a material under hot working condition. These processes unleash the stored energy of deformation and therefore effectively inhibit the localization of strain and the initiation or propagation of microcracks and discontinuities. ${ }^{9)}$ The extent of these processes in an alloy obviously depends on both the material and processing variables. Hence, the combination of intrinsic ductility and the influence of processing variables need to be studied for a given alloy using different workability testing techniques. Hot tensile testing is a fundamental technique that has been widely used to study the hot ductility of metals and alloys. ${ }^{10-14)}$

$\mathrm{Fe}-\mathrm{Ni}$ superalloys such as Incoloy 901 are widely used for high temperature severe applications such as gas turbines and airplane engines. ${ }^{15,16)}$ They are prone to precipitation hardening when aged at high temperatures. ${ }^{17,18)}$ Under hot working condition, dynamic precipitation may happen and use up the strain energy that is also consumed by DRV or DRX. In turn, dynamic precipitation often limits the extent of DRV or DRX, thereby degrading the ductility of material. As a consequence, a safe processing design needs an in-depth knowledge about the the influence of processing variables and intrinsic parameters on the hot ductility. Within the information published so far about the hot ductility of 
superalloys in the open literature, Incoloy 901 has received little attention. Thus, in the current research hot tensile tests have been conducted to elucidate the influence of different deformation conditions on the hot ductility of Incoloy 901.

\section{Experimental Procedures}

The superalloy Incoloy 901 used in this investigation was prepared by casting in a vacuum induction melting furnace with the chemical composition given in Table 1. After VAR and homogenizing for 5 hours at $1140^{\circ} \mathrm{C}$, the ingot was hot rolled to produce an as-rolled wrought alloy for further investigation. Figure 1 shows the starting microstructure of the as-rolled samples before hot tensile testing. The tensile testing samples were prepared according to ASTM E8 standard. Hot tensile tests were carried out at temperatures of $850^{\circ} \mathrm{C}, 950^{\circ} \mathrm{C}, 1050^{\circ} \mathrm{C}$ and $1150^{\circ} \mathrm{C}$ and strain rates of $0.001 \mathrm{~s}^{-1}, 0.01 \mathrm{~s}^{-1}, 0.1 \mathrm{~s}^{-1}$ and $1 \mathrm{~s}^{-1}$. In order to eliminate any temperature gradient in the samples, 10 minutes soaking was performed before testing. After the tests, the deformed samples were quenched in water within 3 seconds to freeze the deformed microstructure for further microstructural investigations. For optical characterization of microstructures, deformed samples were prepared by the standard metallographic techniques and then chemically etched in a reagent composed of $6 \mathrm{ml}$ Sulfuric acid, $3 \mathrm{ml}$ Nitric acid and $2 \mathrm{ml}$ Glycerol.

\section{Results and Discussion}

\subsection{Flow Curves and Constitutive Analysis}

Figure 2 demonstrates the true stress-strain curves at different deformation conditions. It is manifest that as temperature decreases or strain rate is raised the strength level increases and final fracture occurs at lower strain levels. The results are in agreement with the general perception that increasing temperature and decreasing strain rate have positive influence on the ductility of metallic materials. How-

Table 1. Chemical composition of Incoloy 901 studied in current research.

\begin{tabular}{cccccccccccc}
\hline El. & $\mathrm{Ni}$ & $\mathrm{Fe}$ & $\mathrm{Cr}$ & $\mathrm{Mo}$ & $\mathrm{Ti}$ & $\mathrm{Nb}$ & $\mathrm{Co}$ & $\mathrm{Al}$ & $\mathrm{C}$ & $\mathrm{P}$ & $\mathrm{S}$ \\
\hline Wt.\% & 42.62 & 35.19 & 12.73 & 6.12 & 2.32 & 0.15 & 0.65 & 0.19 & 0.021 & 0.005 & 0.003
\end{tabular}

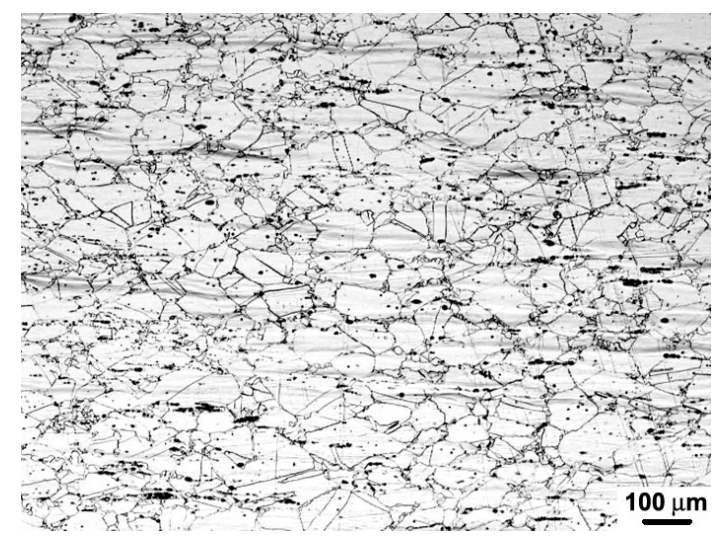

Fig. 1. Starting microstructures of as-hot rolled Incoloy 901 used in this investigation. ever, there is a great deal of evidence that hot ductility might decrease over a specific range of temperature. The phenomenon so-called "hot ductility trough" is mostly associated with the hot tensile testing of some alloys with high amount of Sulfur. ${ }^{19,20)}$ The lack of ductility in such alloys is attributed to the grain boundary weakening that usually stems from the segregation of impurities like Sulfur. In most cases, for alloys susceptible to this kind of hot ductility drop, taking the advantage of ingot refinement processes such as ESR or VAR seems to be a good therapy.

The influence of strain rate on the hot ductility of materials has been somehow controversial because it affects the segregation of solute atoms and the kinetics of dynamic softening processes (DRV and DRX) in different ways. In the previous investigations, it has been reported that increasing strain rate has a positive influence on the hot ductility. ${ }^{19,21,22)}$ This is easily signified by considering the fact that during a high strain rate hot deformation, the detrimental solute atoms have less time to reach the grain boundaries. Hence, increasing strain rate gives rise to better hot ductility. On the other hand, strain rate has a negative influence on the kinetics of DRV or DRX. This is because the fast deformation quickly pumps new dislocations into the structure that is being recovered or recrystallized. The fast concurrent deformation particularly hamper the micromechanisms underlying DRV and DRX, i.e. dislocations annihilation-rearrangement and grain boundary migration, respectively. Thus, in materials without the risk of detrimen-
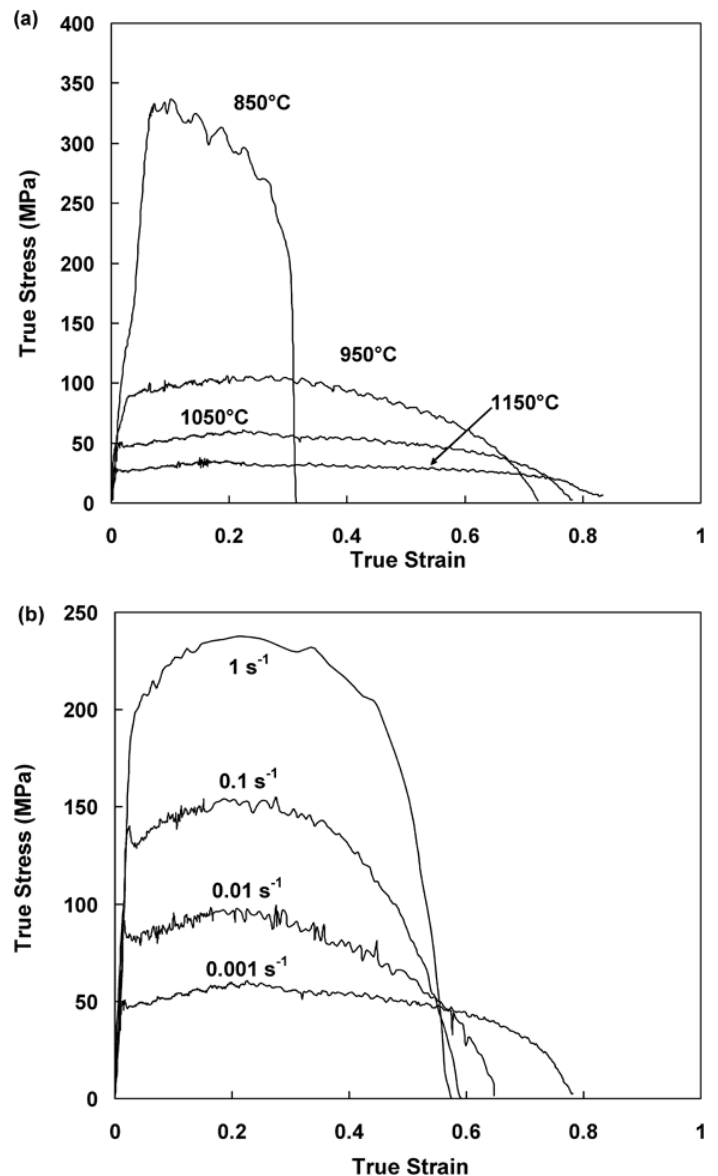

Fig. 2. True stress-strain curves at various deformation regimes (a) constant strain rate of $0.001 \mathrm{~s}^{-1}$, (b) constant tensile temperature of $1050^{\circ} \mathrm{C}$. 


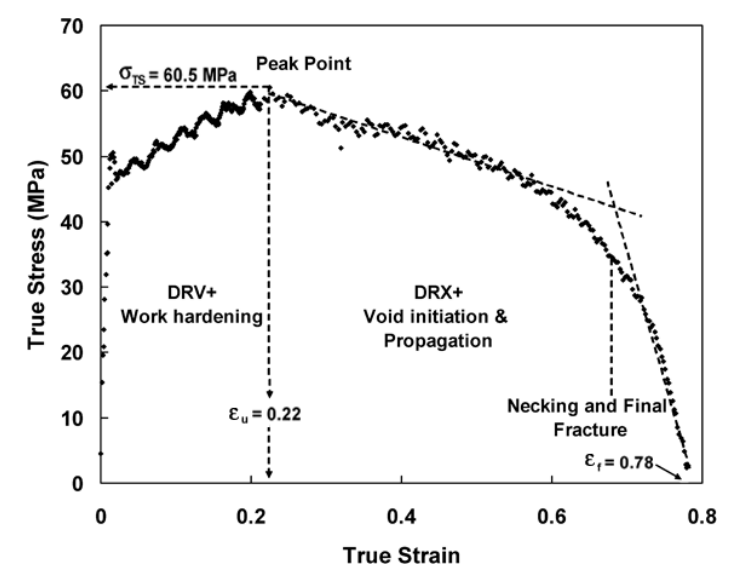

Fig. 3. Underlying microstructural phenomena at different regions of a typical stress-strain curve obtained at $1050^{\circ} \mathrm{C}-0.001 \mathrm{~s}^{-1}$.

tal seggregants, increasing strain rate only weakens DRX and/or DRV, thereby leading to degraded hot ductility.

Figure 3 indicates that a typical true stress-strain curve that is obtained from hot tensile testing is consisted of three regions. The first region comprises the elastic deformation and yielding after which the plastic deformation is controlled by the mutual effects of DRV and work hardening. The plastic deformation up to the peak is required to initiate DRX that causes a flow softening down to the final fracture. At nearly the end of the test, sample is necked and stress decreases rapidly. At this stage, in the microstructure, voids are formed and propagated concurrently with DRX and result in further apparent softening. The test goes to finish with further necking of the sample, coalescence of voids and turning to cracks, crack propagation and final fracture. According to this analysis, whether DRV or DRX occur expeditiously, a better hot ductility will obtain. ${ }^{23)}$

Elongation to fracture and reduction of area are usually used as indices to quantify the influence of deformation variables on the hot ductility. Figures $\mathbf{4}$ and $\mathbf{5}$ show the variation of total elongation and reduction of area with the deformation temperature at different strain rates. Both figures convey the same conclusion that the best hot ductility will be obtained within the temperature range of $950^{\circ} \mathrm{C}-$ $1050^{\circ} \mathrm{C}$. Unfavorable ductility at temperatures below or higher than this range could be ascribed to different reasons. It has been reported that the solvus temperature of $\gamma^{\prime}$ $\left(\mathrm{Ni}_{3}(\mathrm{Al}, \mathrm{Ti})\right)$ and $\eta$ phase $\left(\mathrm{Ni}_{3} \mathrm{Ti}\right)$ precipitates in the studied alloy are about $940^{\circ} \mathrm{C}$ and $995^{\circ} \mathrm{C}$, respectively. ${ }^{24)}$ It is therefore reasonable to agree that hot deformation at $850^{\circ} \mathrm{C}$ would stimulate the dynamic precipitation of $\gamma^{\prime}$ and/or $\eta$ and then the increase of flow stress and decrease of ductility. The sharp increase of tensile (peak) stress $\left(\sigma_{\mathrm{TS}}\right)$ by decreasing temperature from $950^{\circ} \mathrm{C}$ to $850^{\circ} \mathrm{C}$ in Fig. 2(b) can be attributed to the considerable precipitation of second phase particles. By increasing temperature beyond $950^{\circ} \mathrm{C} \mathrm{DRX}$ becomes faster and alleviates the negative influence of dynamic precipitation. The drastic decrease of ductility at temperatures over $1050^{\circ} \mathrm{C}$ that is deduced from decreasing elongation and reduction of area may be associated with the decohesion of the particle/matrix interface that leads to a fast void formation mechanism. This idea should be further verified by microstructural investigations.

The curves also confirm that the lower the strain rate, the

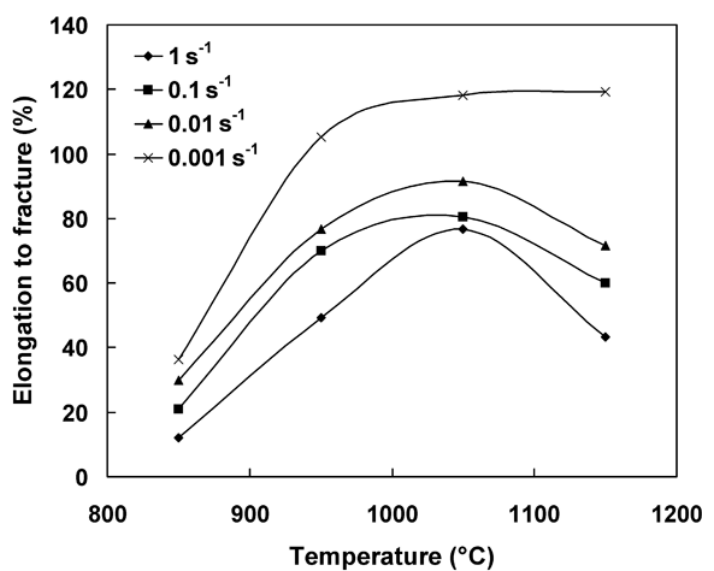

Fig. 4. Total elongation to fracture as a function of tensile temperature at various strain rates.

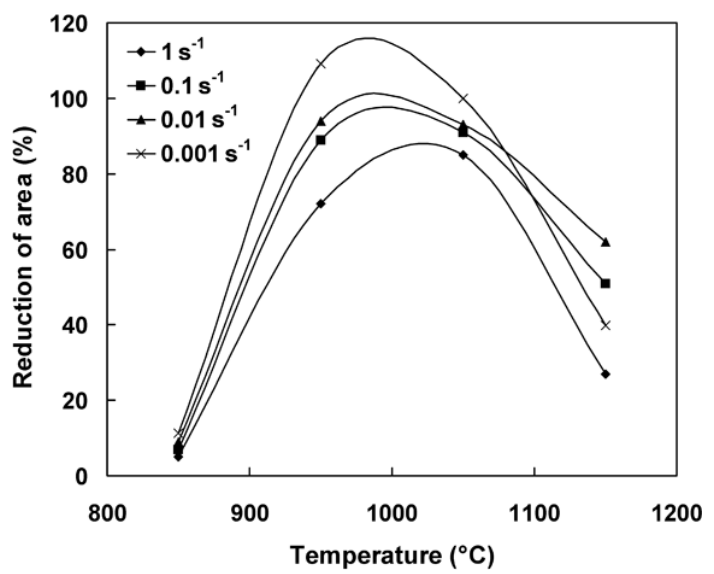

Fig. 5. Reduction of area as a function of tensile temperature at various strain rates.

better ductility is obtained. As before mentioned, strain rate could affect the segregation of solute atoms to grain boundaries and the kinetics of DRX. In the studied alloy VAR effectively minimizes the deleterious effect of solutes and therefore strain rate could only affect the kinetics of DRX. As expected, Figs. 4 and 5 clearly report the negative influence of higher strain rate on the hot ductility that stems from slower DRX.

Figures 6(a) and 6(b) exhibit the dependence of peak (tensile) stress and strain on deformation temperature and strain rate. These results are in agreement with the previous results on the hot ductility of material. At all strain rates, $\sigma_{\mathrm{TS}}$ decreases rapidly as temperature rises to $1050^{\circ} \mathrm{C}$. Then, $\sigma_{\mathrm{TS}}$ decreases gently by increasing temperature in range of $1050^{\circ} \mathrm{C}-1150^{\circ} \mathrm{C}$.

Contrary to the expectations, $\varepsilon_{\mathrm{u}}$ that is the critical strain for the start of DRX has increased with increasing temperature up to $1050^{\circ} \mathrm{C}$. However, beyond $1050^{\circ} \mathrm{C}, \mathcal{E}_{\mathrm{u}}$ normally decreases with further increase in temperature. This anomalous behavior likely stems from the interaction of the dynamic precipitation of second phase particles ( $\gamma^{\prime}$ and/or $\eta$ ) and the DRX of $\gamma$ matrix. At temperatures below $1050^{\circ} \mathrm{C}$, fine particles precede DRX and postpone it to higher strains. With increasing temperature (actually beyond $1050^{\circ} \mathrm{C}$ ) the tendency to precipitation decreases so that DRX occurs in advance. However, coarser particles may form after DRX 

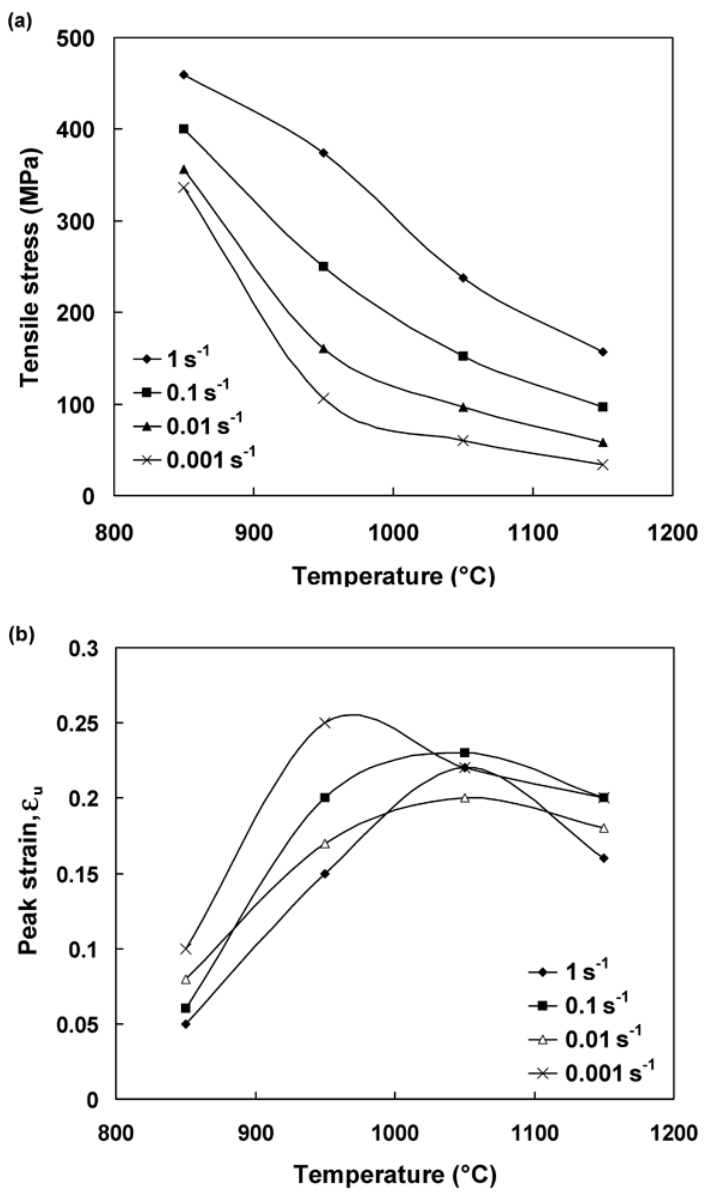

Fig. 6. Variation of (a) tensile (peak) stress, and (b) peak strain of the material as a function of temperature at various strain rates

during post-deformation aging. No doubt that the finer particles that are formed before DRX at temperatures below $1050^{\circ} \mathrm{C}$ has a greater influence on the tensile stress of material as is also confirmed by Fig. 6(a).

The extent of DRX can be simply estimated from the difference between the peak strain, $\mathcal{E}_{\mathrm{u}}$, and fracture strain, $\mathcal{E}_{\mathrm{f}}$, as indicated in Fig. 7. The results confirm that by increasing temperature, DRX occurs more easily and this postpones the final fracture. These results indicate that the better hot ductility in the temperature range of $950^{\circ} \mathrm{C}-1050^{\circ} \mathrm{C}$ can be attributed to faster DRX that postpones the formation of voids and cracks. This effect is more remarkable at lower strain rates such as $0.001 \mathrm{~s}^{-1}$. The remarkable influences of strain rate and temperature on the peak stress and strain (observed in Figs. 6 and 7) can be described by the constitutive equations. These equations not only help in understanding the underlying microstructural phenomena of hot deformation, but also are used in industrial applications. The power-law constitutive equation is the simplest way of describing the tensile stress, given by: $\left.{ }^{25}\right)$

$$
\sigma_{\mathrm{TS}}=\mathrm{K}(\mathrm{T}) \dot{\varepsilon}^{\mathrm{m}}
$$

where, $K(T)$ is a constant that depends on tensile deformation and $\mathrm{m}$ stands for the strain rate sensitivity parameter. It is possible to show that the hot ductility of a material depends also on the value of $\mathrm{m}^{26,27)}$ It actually reflects how much the material withstands against flow localization. When plastic flow is localized in some parts of a workpiece

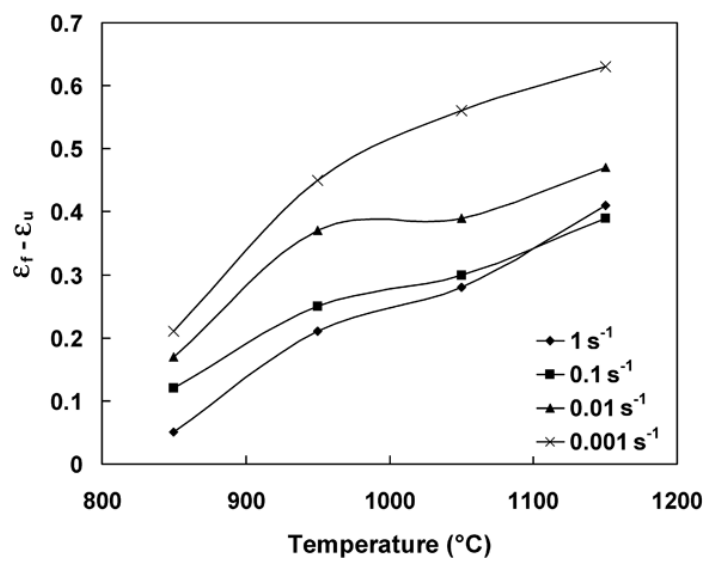

Fig. 7. Difference between peak strain, $\mathcal{E}_{\mathrm{u}}$, and fracture strain, $\mathcal{E}_{\mathrm{f}}$, as a function of tensile temperature.

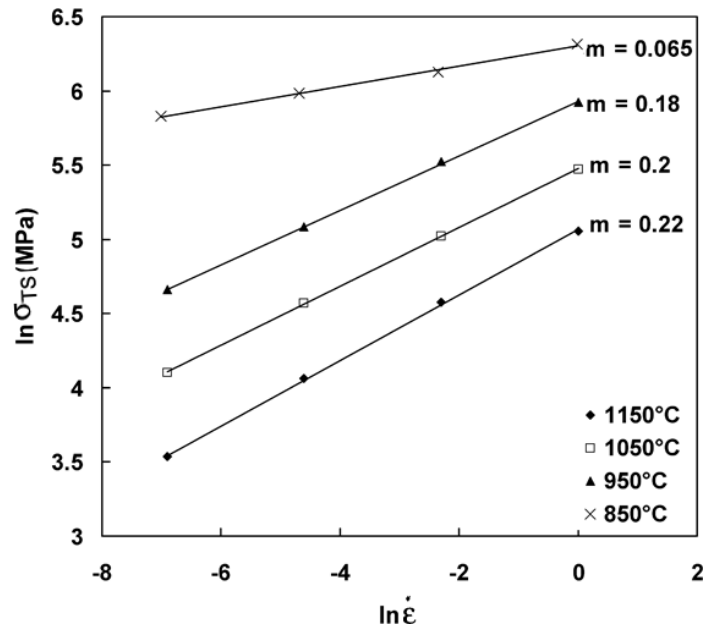

Fig. 8. Variation of tensile stress with strain rate in a logarithmic scale. According to Eq. (1), the slopes gives the values of the strain rate sensitivity parameter.

the strain rate increases locally at those positions. In case of a material with a high value of $\mathrm{m}$, the local increase of strain rate leads to the considerable increase of flow stress (according to Eq. (1)) and stops further plastic deformation within the localized region. Therefore, the plastic strain is transferred to other regions of material with lower strain that leads to homogenously distributed plastic deformation. The values of $\mathrm{K}(\mathrm{T})$ and $\mathrm{m}$ can be determined by drawing the experimental data in a logarithmic scale, as in Fig. 8. Referring to Eq. (1), the slopes of the lines in Fig. 8 give the values of $\mathrm{m}$ and the intercepts are $\mathrm{K}(\mathrm{T})$ at different temperatures. It is clear that the value of $\mathrm{m}$ increases with tensile temperature and in contrast to the previous results (in Figs. 4 and 5) there is no ductility trough at high temperatures such as $1150^{\circ} \mathrm{C}$. It is therefore concluded that the loss of ductility at high temperatures (over $1050^{\circ} \mathrm{C}$ (as indicated in Figs. 4 and 5) is not due to flow localization and as mentioned is likely due to the decohesion of particles/matrix interface. It is also worthy of attention that the value of $\mathrm{m}$ is considerably increases as temperature rises from $850^{\circ} \mathrm{C}$ to $950^{\circ} \mathrm{C}$. As mentioned earlier, the dynamic precipitation of $\gamma^{\prime}$ and $\eta$ intermetallics during hot tensile testing is thought to be extensive at $850^{\circ} \mathrm{C}$. At higher temperatures, faster DRX alleviate the influence of dynamic precipitation and the net 
result will be better ductility.

According to the variations of $\mathrm{m}$ and $\mathrm{K}(\mathrm{T})$ with deformation temperature shown in Fig. 9 the following equations can be combined with Eq. (1) to determine $\sigma_{\mathrm{TS}}$ at a given deformation condition.

$$
\mathrm{K}(\mathrm{T})=-0.0041 \mathrm{~T}+9.78
$$

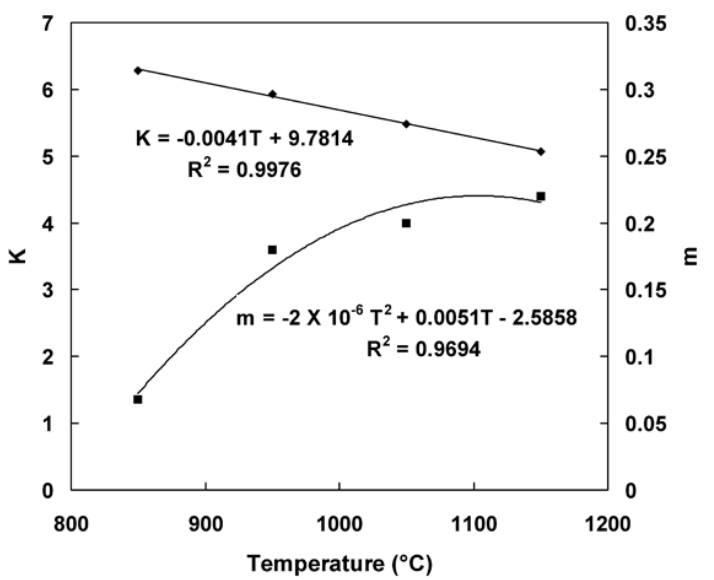

Fig. 9. Variation of coefficient $K(T)$ and $m$ (for Eq. (1)) with tensile temperature.

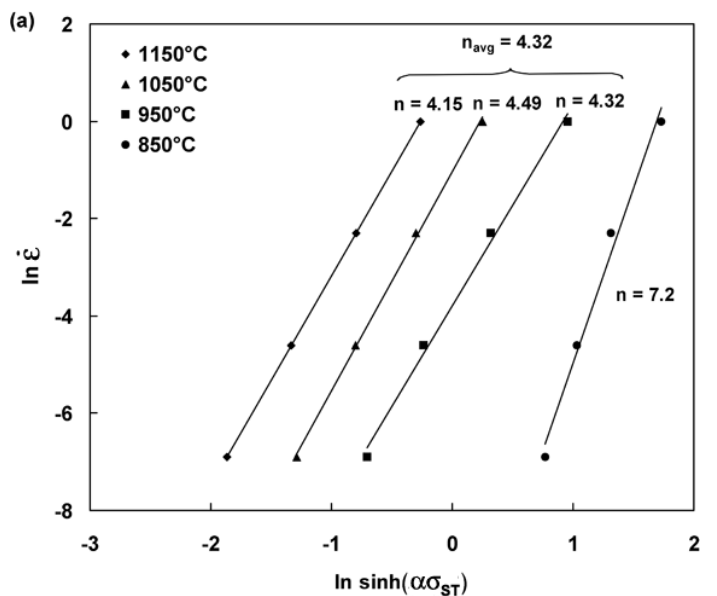

(b)

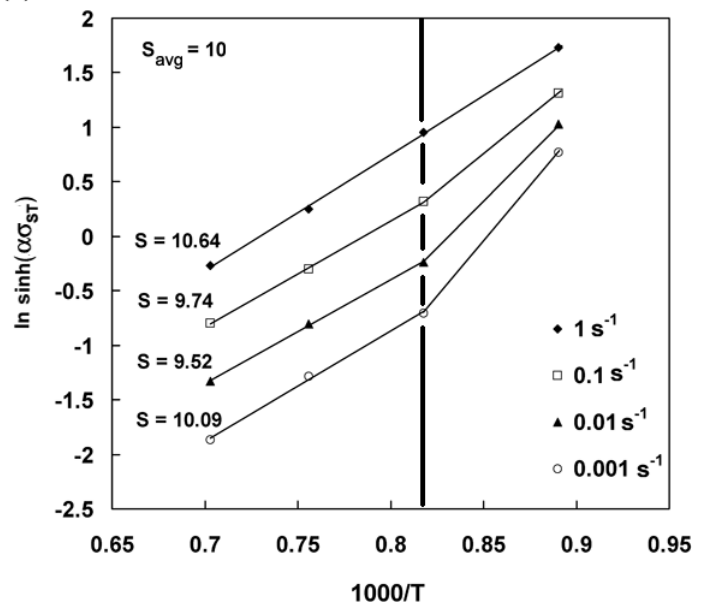

Fig. 10. Variations of tensile stress with (a) strain rate, and (b) the reciprocal of temperature, in the frame of the hyperbolic sine constitutive equation. The notation $\mathrm{S}$ refers to the slope of the curves and equals to $\mathrm{Q} / \mathrm{nR}$ according to Eq. (6)

$$
\mathrm{m}=-2 \times 10^{-6} \mathrm{~T}^{2}+0.0051 \mathrm{~T}-2.59
$$

Figs. 10(a) and 10(b) show the variations of $\sigma_{\text {TS }}$ respectively with strain rate and temperature in the frame of the hyperbolic sine equation. Originally proposed by Garofalo, ${ }^{28)}$ the hyperbolic sine constitutive equation has been widely used to provide accurate prediction of flow stress under hot working condition. ${ }^{29)}$ The hyperbolic sine constitutive equation is given as follows:

$$
\mathrm{Z}=\dot{\varepsilon} \exp \left(\frac{\mathrm{Q}}{\mathrm{RT}}\right)=\mathrm{A}\left\{\sinh \left(\alpha \sigma_{\mathrm{TS}}\right)\right\}^{\mathrm{n}}
$$

where, $\mathrm{Z}$ is Zener-Hollomon parameter, $\mathrm{Q}$ stands for the apparent activation energy and $\mathrm{A}, \mathrm{n}$ and $\alpha$ are the material constants.

Since, Eq. (4) is differentiated as in Eq. (5), the value of $\mathrm{n}$ can be determined by drawing $\ln \left\{\sinh \left(\alpha \sigma_{\mathrm{TS}}\right)\right\}$ versus strain rate at a given strain and deformation temperature.

$$
\mathrm{n}=\left[\frac{\partial \ln \varepsilon^{\circ}}{\partial \ln \left\{\sinh \left(\alpha \sigma_{\mathrm{TS}}\right)\right\}}\right]_{\varepsilon, \mathrm{T}}
$$

As seen in Fig. 10(a), the values of $\mathrm{n}$ at temperatures of $950^{\circ} \mathrm{C}, 1050^{\circ} \mathrm{C}$ and $1150^{\circ} \mathrm{C}$ are near and can be averaged as 4.32 ; whereas, by decreasing temperature to $850^{\circ} \mathrm{C}, \mathrm{n}$ sharply increases to 7.2. These results again highlight a change in the mechanism of microstructural evolution by decreasing temperature. As mentioned earlier, these anomalous results can be attributed to the extensive dynamic precipitation of second phase particles. It should be noted that the value of $\alpha$ has adopted as 0.0045 by try and error so that to bring the lines in Fig. 10(a) to the most parallel and linear condition.

The apparent activation energy for hot deformation can be determined by differentiating $\ln \left\{\sinh \left(\alpha \sigma_{\mathrm{TS}}\right)\right\}$ with respect to $1 / \mathrm{T}$ in Eq. (4), as follows:

$$
\mathrm{Q}=\operatorname{Rn}\left[\frac{\partial \ln \sinh \left(\alpha \sigma_{\mathrm{TS}}\right)}{\partial(1 / \mathrm{T})}\right]_{\dot{\varepsilon}, \varepsilon}
$$

The partial differential term in Eq. (6) refers to the average slope of the curves plotted in Fig. 10(b) that was determined about 10000 . The change of slope at temperatures below $950^{\circ} \mathrm{C}$ is observed in agreement with the previous results. By using Eq. (6), the average value of $Q$ at the peak strain is calculated as $359.2 \mathrm{~kJ} / \mathrm{mol}$ while this value for $850^{\circ} \mathrm{C}$ can be calculated as high as $900 \mathrm{~kJ} / \mathrm{mol}$. The sharp increase of the apparent activation energy at $850^{\circ} \mathrm{C}$ reflects much more resistance to deformation at this temperature that corroborates the idea of strengthening by precipitation. The various values of Q $\left(350-470 \mathrm{~kJ} / \mathrm{mol}^{29-32)}\right)$ that have been reported for different kinds of superalloys of Co-based, Fe-based and Ni-based types implies that this parameter strongly depends on the chemical composition as well as the deformation conditions. It is well-known that the volume fraction of the strengthening second phase particles strongly depends on the chemical composition of the superalloys. Therefore, as mentioned before both the chemical composition and the deformation condition controls the final hot ductility of the alloy. To reconstruct Eq. (4) for the studied material, the coefficient A was determined as $4.33 \times 10^{13}$ by drawing the variation of $\ln \left[\sinh \left(\alpha \sigma_{\mathrm{TS}}\right)\right]$ versus the $\mathrm{Z}$ parameter (as the intercept of the curve) in Fig. 11. Equation (4) can be gen- 


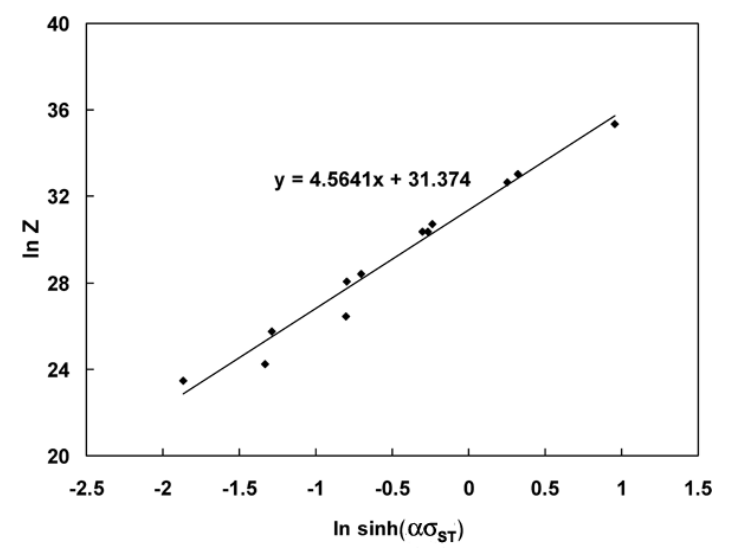

Fig. 11. Hyperbolic sine of tensile stress as a function of ZenerHollomon parameter at all studied deformation temperatures and strain rates.

eralized to the industrial condition to determine the tensile stress of the material at different temperatures and strain rates.

\subsection{Microstructural Observations}

In order to verify the mechanical testing results and signify the discussions of the previous section optical microscopy observations were carried out on the deformed samples at necking and the position corresponding to true strain of 0.7 . It is to be noted that the position with strain of 0.7 is located at different places on the deformed samples due to the inhomogenous plastic deformation. Figure 12 presents the micrographs of deformed samples at various temperatures and strain rate of $0.001 \mathrm{~s}^{-1}$. In agreement with the results of mechanical testing shown in Figs. 8 and 10, Fig. 12 indicates that at $850^{\circ} \mathrm{C}$ fine dynamically formed precipitates (likely $\gamma^{\prime}$ particles) have effectively inhibit DRX before fracture. The fine precipitates arrowed in Fig. 12(a) have pinned the grain boundaries and elongated grains clearly signify the absence of DRX. This observation is also confirmed by low ductility of the material in Figs. 4 and 5 . Therefore, the small difference between $\varepsilon_{\mathrm{u}}$ and $\varepsilon_{\mathrm{f}}$ at $850^{\circ} \mathrm{C}$ in Fig. 7 can be attributed to the initiation and propagation of cavities (observed in Fig. 12(a)) before fracture and not to the effect of DRX. At temperatures of $950^{\circ} \mathrm{C}-1150^{\circ} \mathrm{C}$, Figs. 12(b) to 12(d) indicate that DRX has occurred and resulted to fine equiaxic grain structure; while fine precipitates that are likely $\eta\left(\mathrm{Ni}_{3} \mathrm{Ti}\right.$ with solvus temperature of $995^{\circ} \mathrm{C}^{24)}$ ) are presented within the grains. It seems that their size is larger than it required to effectively pin the grain boundaries. Figure 13 compares the precipitation conditions at $850^{\circ} \mathrm{C}$ and $1150^{\circ} \mathrm{C}$ in magnified micrographs. In both temperatures, the second-phase particles are preferential places for the formation of cavities that are usually coalesce along the grain boundaries and form micro-cracks. However, at $1150^{\circ} \mathrm{C}$, due to the less volume fraction of particles the voids are smaller and their coalescence to form microcracks occurs at higher strains.

The influence of strain rate on the microstructural evolution of the samples hot deformed at temperature of $1050^{\circ} \mathrm{C}$ is indicated in Fig. 14. It is apparent that the increasing strain rate results in a considerable refinement of the grain structure and leads to a finer grain size. This is well-known
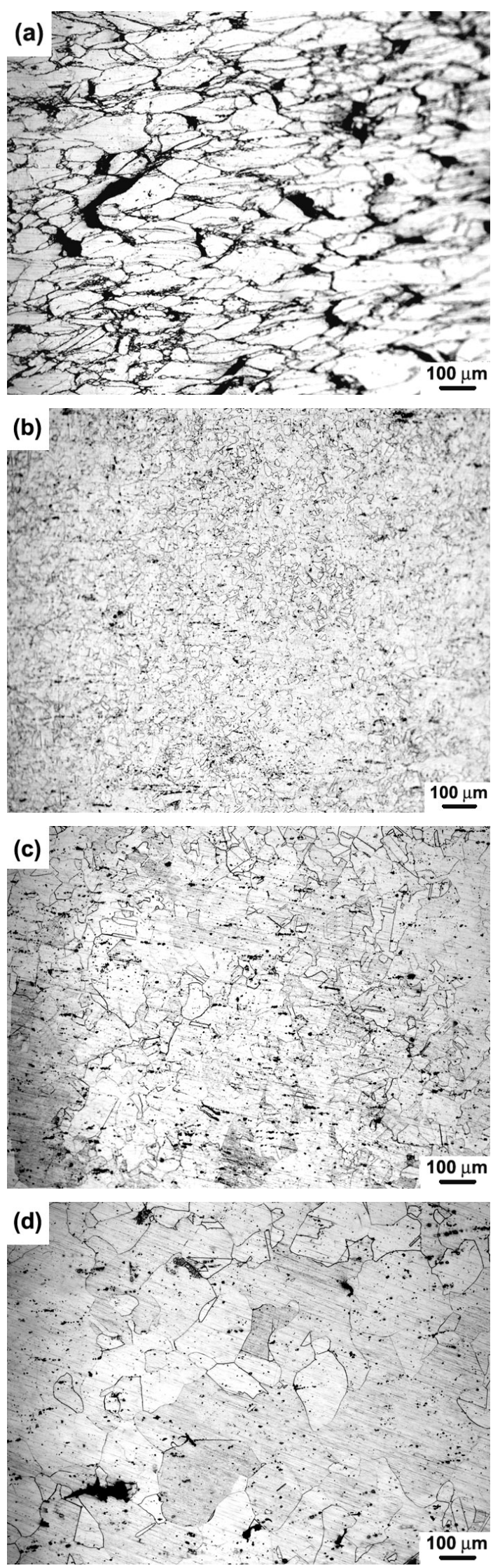

Fig. 12. Microstructures of the deformed samples at strain of 0.7 and strain rate of $0.001 \mathrm{~s}^{-1}$ : (a) $850^{\circ} \mathrm{C}$, (b) $950^{\circ} \mathrm{C}$, (c) $1050^{\circ} \mathrm{C}$, and $(\mathrm{d}) 1150^{\circ} \mathrm{C}$.

that increasing strain rate decreases the growth rate of new DRX grains and gives rise to a finer grain size. Although getting a finer grain size is desirable, as indicated in Figs. 4 

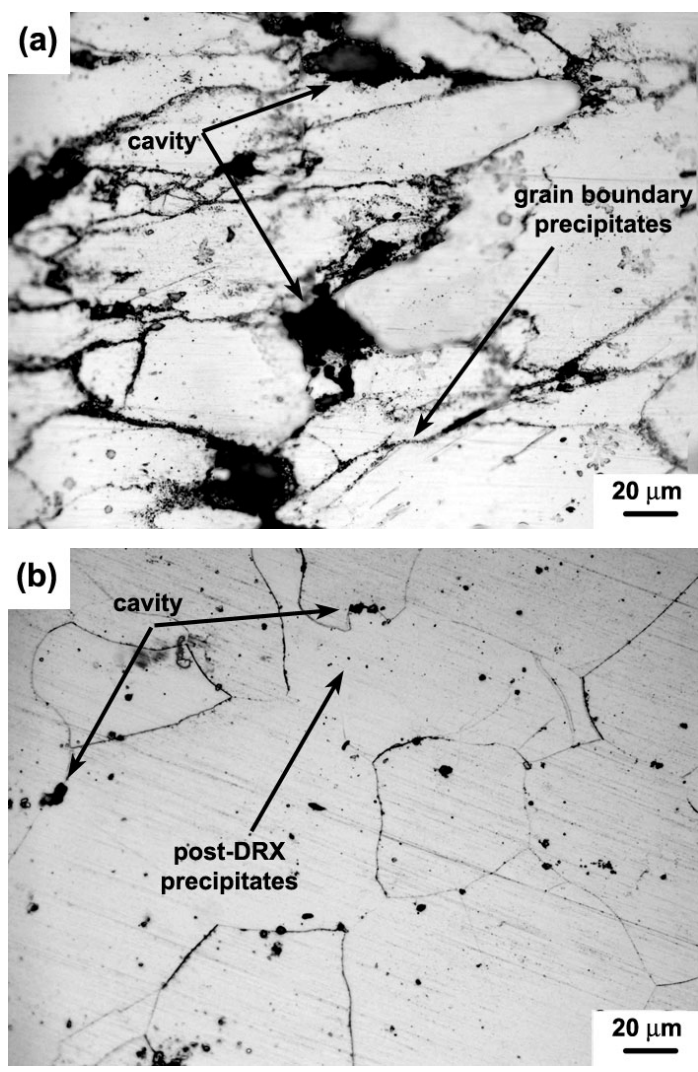

Fig. 13. Typical micrographs the deformed samples at strain of 0.7 and strain rate of $0.001 \mathrm{~s}^{-1}$ indicating the precipitation and cavities: (a) $850^{\circ} \mathrm{C}$, and (b) $1150^{\circ} \mathrm{C}$.

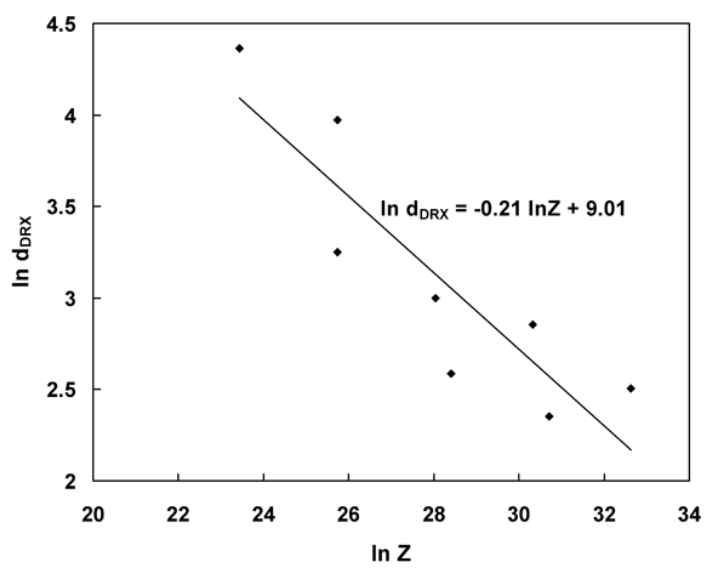

Fig. 15. Dependence of average DRX grain size $\left(d_{D R X}\right)$ on the Zener-Hollomon parameter.

and 5, but increasing strain rate decreases the softening capacity of DRX and the degradation of hot ductility is a concern that should be considered. Figure 15 shows the dependence of DRX grain size on the Zener-Hollomon parameter and provides a regression model as follows that makes a rough prediction of average grain size at different deformation regimes:

$$
\mathrm{d}_{\text {DRX }}=8184.5 Z^{-0.21}
$$

\section{Conclusions}

Hot tensile testing was conducted at different tempera-
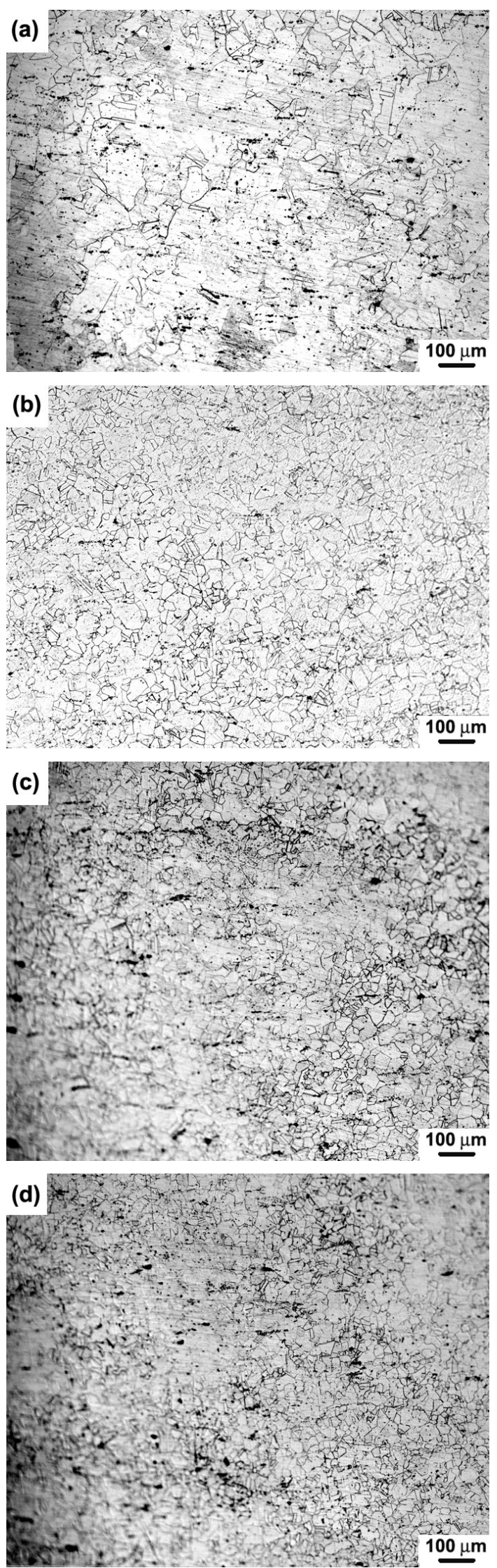

Fig. 14. Microstructures of the deformed samples at strain of 0.7 and constant temperature of $1050^{\circ} \mathrm{C}$ and various strain rates of (a) $0.001 \mathrm{~s}^{-1}$, (b) $0.01 \mathrm{~s}^{-1}$, (c) $0.1 \mathrm{~s}^{-1}$, and (d) $1 \mathrm{~s}^{-1}$.

tures and strain rates to study the hot ductility of Incoloy 901 and the underlying phenomena. The major results of this research can be drawn as follows: 
(1) Hot ductility of the material increased with increasing temperature up to $1050^{\circ} \mathrm{C}$ and descended at higher temperatures. Better ductility at high temperatures was attributed to the influence of dynamic recrystallization. Due to the ingot refining via VAR process, hot ductility trough was not observed within the studied temperature range.

(2) At $850^{\circ} \mathrm{C}$, dynamic precipitation of intermetallic phases could effectively inhibit dynamic recrystallization and resulted in poor hot ductility.

(3) The hot ductility loss at temperatures beyond $1050^{\circ} \mathrm{C}$ was associated with the decohesion of intermetallic particles/matrix interface.

(4) The strain rate sensitivity of material increased as a function of temperature. The material was found insensitive to flow localization over the studied temperature and strain rate.

(5) The peak strain of the material unexpectedly increased with increasing temperature up to $1050^{\circ} \mathrm{C}$ and then decreased at higher temperatures. These results could be accounted for by considering the possibility of dynamic precipitation of intermetallics at temperatures below $1050^{\circ} \mathrm{C}$ and thereby delaying dynamic recrystallization.

(6) The hyperbolic sine constitutive equation was used to describe the dependence of tensile stress on deformation temperature and strain rate. The material constants of n, $\alpha$ and $\mathrm{A}$ were determined. The apparent activation energy was determined as $359 \mathrm{~kJ} \mathrm{~mol}^{-1}$. The values of $\mathrm{n}$ and $\mathrm{Q}$ were remarkably higher for deformation below $950^{\circ} \mathrm{C}$ and emphasized on more deformation resistance due to precipitation.

\section{REFERENCES}

1) G. Bai, J. Li, R. Hu, Z. Tang, X. Xue and H. Fu: Mater. Sci. Eng., A528 (2011), 1974.

2) E. Liu, S. Sun, G. Tu1, Z. Zheng, X. Guan and L. Zhang: J. Mater. Sci. Technol., 25 (2009), 727.

3) Y. Lu, J. Liu, X. Li, J. Liang, Z. Li, G. Wu and X. Zhou: Trans. Nonferrous Met. Soc. China, 22 (2012), s84.
4) C. Qiu, X. Wu, J. Mei, P. Andrews and W. Voice: J. Alloys Compd., 578 (2013), 454.

5) X. D. Lu, J. H. Du, Q. Deng and Z. Y. Zhong: J. Alloys Compd., 486 (2009), 195.

6) S.-H. Song, Z.-X. Yuan, J. Jia, D.-D. Shen and A.-M. Guo: Metall. Mater. Trans., A34 (2003), 1611.

7) A. Choudhury: ISIJ Int., 32 (1992), 563.

8) K. Takachio and T. Nonomura: ISIJ Int., 36 (1996), S85.

9) E. López-Chipres, I. Mejía, C. Maldonado, A. Bedolla-Jacuinde and J. M. Cabrera: Mater. Sci. Eng., A460-461 (2007), 464.

10) L. H. Chown and L. A. Cornish: Mater. Sci. Eng., A494 (2008), 263.

11) T. Revaux, P. Deprez, J.-P. Bricout and J. Oudin: ISIJ Int., 34 (1994), 528.

12) W. Ozgowicz: J. Mater. Proc. Technol., 162-163 (2005), 392.

13) S. C. Seo, K. S. Son, S. K. Lee, I. Kim, T. J. Lee, C. Yim and D. Kim: Metal. Mater. Int., 14 (2008), 559.

14) J. Xiao, D. S. Li, X.Q. Li and T. S. Deng: J. Alloys Compd., 541 (2012), 346.

15) R. B. Frank and R. K. Mahidhara: Proc. of 6th Int. Symp. on Superalloys ed. by S. Reichman, D. N. Duhl, G. Maurer, S. Antolovich and C. Lund, TMS-AIME, Warrendale, PA, (1988).

16) M. J. Donachie and S. J. Donachie: Mechanical Engineers' Handbook, Materials and Mechanical Design, Volume 1, 3rd ed., ed. by M. Kutz, John Wiley \& Sons, Inc., Hoboken, NJ, (2006), DOI: 10.1002/ 0471777447.ch8

17) K. Kusabiraki, E. Amada and T. Ooka: ISIJ Int., 36 (1996), 208.

18) K. Nakai, Y. Ohara, H. Ohtsubo and Y. Ohmori: ISIJ Int., 36 (1996), 187.

19) M. Yazdani, S. M. Abbasi, A. Momeni and A. Karimi Taheri: Mater. Design, 32 (2011), 2956.

20) T. Kizu and T. Urabe: ISIJ Int., 49 (2009), 1424.

21) B. Mintz, R. Abushosha and J. J. Jonas: ISIJ Int., 32 (1992), 241.

22) S. Hutta, T. Murakami, T. Narushima, Y. Iguchi and C. Ouchi: ISIJ Int., 45 (2005), 338.

23) B. López and J. J. Urcola: Mater. Sci. Technol., 12 (1996), 673.

24) ASM Specialty Handbook: Heat Resistant Materials, ASM International, Materials Park, Ohio, (1997), 295.

25) J. Deng, Y. C. Lin, S. S. Li, J. Chen and Y. Ding: Mater. Design, 49 (2013), 209.

26) Y. C. Huang, Y. C. Lin, J. Deng, G. Liu and M. S. Chen: Mater. Design, 53 (2014), 349.

27) A. Momeni, K. Dehghani, G. R. Ebrahimi and H. Keshmiri: Metall. Mater. Trans., 41A (2010), 2898.

28) F. Garofalo: Trans. AIME, 227 (1963), 351.

29) H. Dehghan, S. M. Abbasi, A. Momeni and A. Karimi Taheri: $J$. Alloys Compd., 564 (2013), 13.

30) D. Cai, L. Xiong, W. Liu, G. Sun and M. Yao: Mater. Charact., 58 (2007), 941.

31) C. Tang, F. Pan, X. Qu, B. Duan, T. Wang and X. He: Rare Metals, 27 (2008), 292.

32) Y. Wang, W. Z. Shao, L. Zhen, L. Yang and X. M. Zhang: Mater. Sci. Eng., A498 (2008), 479. 